\title{
Genetic discrimination: Too few data
}

\author{
Margaret F Otlowski ${ }^{*, 1}$, Sandra D Taylor ${ }^{2}$ and Kristine K Barlow-Stewart ${ }^{3}$ \\ ${ }^{1}$ Faculty of Law, University of Tasmania, Australia; ${ }^{2}$ School of Social Work and Social Policy, The University of \\ Queensland, Australia; ${ }^{3}$ The Centre for Genetics Education, Royal North Shore Hospital, New South Wales, Australia
}

European Journal of Human Genetics (2003) 11, 1-2. doi:10.1038/sj.ejhg.5200910

Reports of discrimination based on genetic test results have been documented in overseas jurisdictions since the early 1990s, including the United States ${ }^{1}$ and the United Kingdom, ${ }^{2}$ but it is only in more recent years that evidence has been emerging that genetic discrimination is also occurring in Australia. ${ }^{3}$ Following the first documented case study of genetic discrimination in Australia by Dr Sandy Taylor in 1998, ${ }^{4}$ two further Australian-based studies undertaken by Dr Kristine Barlow Stewart and David Keays have identified a total of 48 reported cases of genetic discrimination, primarily in the insurance and employment contexts. ${ }^{5}$ As accounts of genetic discrimination in Australia have come to light, interest in this newly emerging phenomenon, and concern about its implications for individuals affected, have been increasing. This growing level of concern is highlighted in the current national inquiry being undertaken in Australia by the Australian Federal Government which will examine the protection of human genetic information, with a strong focus on genetic discrimination. ${ }^{6}$

The wide-ranging consequences of genetic discrimination, both for the individual concerned and society as a whole, have been outlined in a growing body of literature on the subject ${ }^{7}$ and genetic discrimination has been recognised internationally as a human rights issue which carries significant social, legal and policy implications. ${ }^{8}$ Discrimination against individuals on the basis of genetic factors has the potential to generate significant social, health and economic burdens for society as it diminishes the opportunities of genetically at-risk individuals in a range of contexts (for example insurance, employment) and for some, may also impact upon potentially helpful engagement with preventive genetic medicine. Whilst there appears to be a growing acceptance across a number of jurisdictions, including Australia, that reform initiatives

*Correspondence: MF Otlowski, Faculty of Law, University of Tasmania, Australia. Tel: 613 62267569; Fax: 613 62267623;

E-mail: margaret.otlowski@utas.edu.au

Received 4 June 2002; revised 18 September 2002; accepted 24 September 2002 are required to tackle the problem of genetic discrimination, there is less agreement about what form such reform measures should take. In developing and later evaluating reform initiatives in this area, it is clearly an advantage to be able to draw on reliable empirical data documenting the nature and extent of the problem.

Research which validates the claim that genetic discrimination is occurring has been limited, both in scope and design. There has, as yet, been no comprehensive co-ordinated empirical research about the nature and extent of genetic discrimination across countries where genetic services are highly developed. More significantly, the studies undertaken to date rely predominantly on unverified and in many instances, anonymous accounts of individuals' subjective impressions of whether they received inequitable treatment from third parties such as employers or insurers. Although new initiatives are now being undertaken within the insurance industry in this regard, ${ }^{9}$ there has also been a general absence of systematic documentation research into current third party policies and practices, by which responses to issues associated with the genetic profiles of individuals are determined. Because of such limitations, studies of genetic discrimination to date should be viewed with caution. ${ }^{10}$ Whilst they establish that individuals may believe that they have been discriminated against on the basis of genetic factors, they leave little scope for objective assessment of the alleged discrimination: whether it was without legal justification and therefore unlawful, or whether it may have been legally justified pursuant to the exemptions that both insurers and employers have from disability discrimination. ${ }^{11}$ Therefore comprehensive investigations of genetic discrimination in regions where genetic tests are available are urgently needed.

\footnotetext{
${ }^{1}$ Billings et al: Discrimination as a Consequence of Genetic Testing,' (1992) 50, American Journal of Human Genetics, 476; Geller, L et al: Individual, Family and Societal Dimensions of Genetic Discrimination: A Case Study Analysis', 1996 2, Science and Engineering Ethics 71; Lapham, E. et al, 'Genetic Discrimination: Perspectives of Consumers' (1996) 274, Science 62.
} 
Genetic discrimination MF Otlowski et al

${ }^{2}$ Low L, King S, Wilkie T: 'Genetic Discrimination in Life Insurance: Empirical Evidence from a Cross Sectional Survey of Genetic Support Groups in the United Kingdom' (1998) 317, British Medical Journal 1632.

${ }^{3}$ Taylor S: 'A Case Study of Genetic Discrimination: Social Work and Advocacy in a New Context' (1998) 51, Australian Social Work 51; Barlow-Stewart K and Keas D: 'Genetic Discrimination in Australia' (2001) 8, Journal of Law and Medicine 250; Keas D: 'When is Genetic Discrimination Justified?' (2000) 19 Monas Bioethics Review 79.

${ }^{4}$ Taylor: 'A Case Study of Genetic Discrimination: Social Work and Advocacy in a New Context' above.

${ }^{5}$ Barlow-Stewart and Keas 'Genetic Discrimination in Australia,' above and Keas, 'When is Genetic Discrimination Justified?' above.

${ }^{6}$ Media release, 9 August 2000, Attorney-General Daryl Williams, Minister for Health, Michael Wooldridge. The website address for details of the Terms of Reference and other information is http//www.alrc.gov.au/index.html. In November 2001 an Issues Paper was released seeking submissions and a round of public meetings was undertaken. This has since been followed by the release of a Discussion Paper in August 2002. The inquiry is due to report back in March 2003 (the origihal time-frame of mid 2002 having been extended).

${ }^{7}$ Billings P et al: 'Discrimination as a Consequence of Genetic Testing' (1992) 50, American Journal of Human Genetics 476; Marteau T and
Richards M (eds): The Troubled Helix: Social and Psychological Implications of the New Human Genetics (1995) Cambridge University Press, Cambridge; Burley J: The Genetic Revolution and Human Rights The Oxford Amnesty Lectures 1998 (1999) Oxford University Press, Oxford; Peters T (ed): Genetics: Issues of Social Justice (1998) Pilgrim Press, Ohio; BarlowStewart and Keas: 'Genetic Discrimination in Australia,' above.

${ }^{8}$ Council of Europe Bioethics Convention on Human Rights Biomedicine (1996); UNESCO Universal Declaration on the Human Genome and Human Rights (1997): see Burley J: The Genetic Revolution and Human Rights The Oxford Amnesty Lectures 1998 (1999) Oxford University Press, Oxford; Peters T (ed): Genetics: Issues of Social Justice (1998) Pilgrim Press, Ohio.

${ }^{9}$ The peak body IFSA has commissioned the Institute of Actuaries of Australia to undertake periodic surveys of life insurers to gauge the number of applications that they are receiving that disclose genetic test results and the life insurers' decisions in relation to these applications.

${ }^{10}$ McGlennan T: Insurance and Genetic Information, Association of British Insurers Research Report 2001, 44-45.

${ }^{11}$ See Disability and Discrimination Act 1992 (Ch) ss 46 and s 15(4)(b) respectively and equivalent state and territory legislation.

European Journal of Human Genetics 